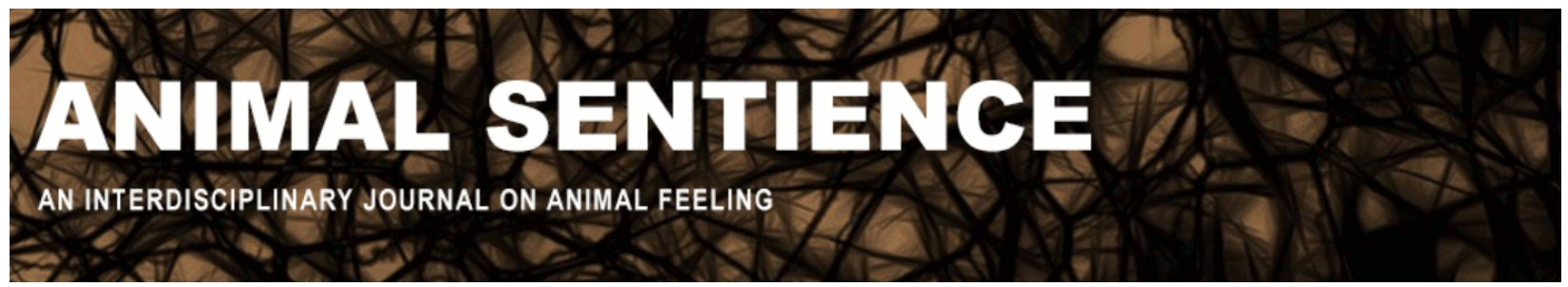

Derbyshire, Stuart W.G. (2016) Fish lack the brains and the psychology for pain. Animal Sentience 3(18)

DOI: $10.51291 / 2377-7478.1047$

Date of submission: $2015-10-22$

Date of acceptance: 2015-12-13

(c)

This article has appeared in the journal Animal

Sentience, a peer-reviewed journal on animal

cognition and feeling. It has been made open access,

free for all, by WellBeing International and deposited

in the WBI Studies Repository. For more information,

please contact

wbisr-info@wellbeingintl.org.

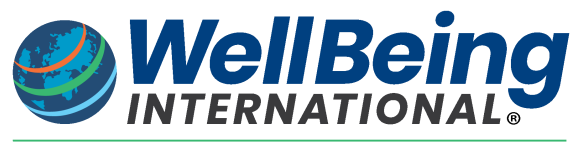

SOLUTIONS FOR PEOPLE, ANIMALS AND ENVIRONMENT 


\title{
Fish lack the brains and the psychology for pain
}

\author{
Commentary on Key on Fish Pain
}

\author{
Stuart W. G. Derbyshire \\ Department of Psychology \\ National University of Singapore
}

\begin{abstract}
Debate about the possibility of fish pain focuses largely on the fish's lack of the cortex considered necessary for generating pain. That view is appealing because it avoids relatively abstract debate about the nature of pain experience and subjectivity. Unfortunately, however, that debate cannot be entirely avoided. Subcortical circuits in the fish might support an immediate, raw, "pain" experience. The necessity of the cortex only becomes obvious when considering pain as an explicitly felt subjective experience. Attributing pain to fish only seems absurd when pain is considered as a state of explicit knowing.
\end{abstract}

Stuart W. G. Derbyshire psydswg@nus.edu.sg is an Associate Professor at the National University of Singapore in the Department of Psychology and the A*STAR-NUS Clinical Imaging Research Centre. His main research interest is the neurobiology of pain, especially as it relates to issues of consciousness, subjectivity and ongoing pain in the absence of injury.

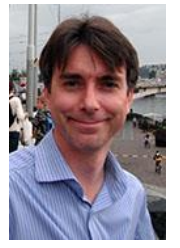
http://www.fas.nus.edu.sg/psy/_people/derbyshire.htm

The past twenty years have seen increasing discussion of what organisms may or may not feel pain with articles addressing the potential pain of crustaceans (Elwood, 2011), fetuses (Lowery et al., 2007) and fish (Braithwaite, 2007). In each case the argument follows a similar trajectory. First, there is the discovery of some part of the neural system for pain: opioid receptors in the lobster (Caseres et al., 2005), the HPA axis in the fetus (Giannakoulopoulos et al., 1994), and C-fibres in fish (Sneddon et al., 2003a). That discovery is integrated into a larger framework supporting the experience of pain: avoidance learning in crabs (Appel and Elwood, 2009), facial grimacing in the fetus (Reissland et al., 2013), and loss of neophobia in fish (Sneddon et al., 2003b). Finally, there is the suggestion that certain practices should be stopped to prevent pain: lobsters should no longer be boiled alive; abortion should be restricted to 20 weeks; and fish should not be hooked. These arguments are followed by rebuttals from investigators who do not accept that pain is relevant to such practices (Derbyshire, 2006; Rose, 2007).

On the whole, I am on the side of those who believe that the term "pain" is being used too casually and so I welcome Key's (2016) contribution to the argument against fish pain. Key covers the essential literature explaining why pain requires a cortex in order to be experienced and why fish, which lack a cortex, cannot experience pain. Key dismisses the possibility that pain might be subcortical because complete ablation of the cortex results in complete loss of conscious sensory perception and loss of thalamic projections into S1 prevent pain sensation. Thus, concludes Key, the cortex is necessary for pain experience. 
The case against fish pain, therefore, appears straightforward and compelling: fish cannot feel pain because they do not have the brains for it. Anyone maintaining the notion of fish pain is either ignorant as to the facts of fish neurology, or is in the grip of an unreasonable anthropomorphism, or both.

I have considerable sympathy with that argument and with the suggestion that the cortex is necessary for pain sensation. At the same time, however, Key's argument is largely silent on the nature of pain and subjective experience more broadly. Consequently, his entire case against fish pain rests on whether it is accepted that the fish nervous system is inadequate to generate pain. Bluntly put, that case is not accepted. The discovery of fish nociceptors, with functional connections into the fish tegmentum (Sneddon et al., 2003a; Dunlop and Laming, 2005), combined with adaptive changes in behavior following noxious stimulation (Sneddon et al., 2003b), are interpreted by some as supporting an experience of pain in fish (Braithwaite, 2007; Sneddon, 2009).

Others also suggest that brainstem circuits can generate pain, which likewise supports the case for fish pain (Devor et al., 2014). Evidence that the brainstem might support pain includes experiences with anencephalic infants who express emotion despite missing large portions of their cortex (Merker, 2007), activation studies demonstrating brainstemmediated feelings in normal volunteers (Damasio and Carvalho, 2013), and fetal withdrawal and stress responses to noxious stimulation before cortical development (Giannakoulopoulos et al., 1994).

Fish may not have the complex brains of the higher mammals, but they do have a nervous system that can detect noxious stimulation, and they demonstrate a behavioural response to noxious stimulation. Some call that pain because they understand pain as an awareness of an objective bodily state - the immediate sensory representation of tissue damage (Grahek, 2007). Such an experience does not need a cortex because the experience is raw, tied directly to the immediate damage, and is an objective extension of that damage, which drives the aversive behavioural responses.

Thus the argument for fish pain relies on a distinction, not always acknowledged, between the immediate state of being in pain and the explicit knowledge that one is in pain (Tallis, 2005). Damasio and Carvalho (2013) make a similar distinction between feelings, as the expression of a bodily state, and emotions, as that same state in the context of the person's environment and understanding.

The distinction between "being that" and "knowing that" sounds like one that can work. That distinction allows for pain in the fish to be substantially different from pain as felt by an adult person. Fish pain will not involve explicitly identifiable negative sensations, generating fear, concern, and consciously organized protective behavior. Fish pain will be much less elaborate, involving something apprehended, as an immediacy, but not comprehended, as an unwelcome intrusion into the subjective being of fish (Derbyshire \& Anand, 2011).

An apprehended immediacy is not a subjective experience and will not be felt in any manner approaching what is usually meant by the term "felt." There are many apprehended immediacies that will float in and out of the fish nervous system: changes in temperature, 
ambient motion, light and so on, constantly arriving and disappearing and vying for dominance. Any fish experience will be part of a fragment, unconnected to a psychological self, and thus quite unlike our experiences. Any immediate apprehension that might accompany noxious stimulation in the fish, therefore, should not be called pain because it is clearly far from the typical pain experience that we know. Use of the term "pain" is mischievous; it unreasonably invites equivalence between what we would expect to feel when hooked and what a fish will feel when hooked.

To feel pain, or anything else, as an explicit subjective state, requires a conceptual psychological subject to do the feeling. Fish lack the brains and the psychological development necessary to become subjective beings, and that is why fish do not feel pain.

\section{References}

Appel, M. and Elwood, R.W. (2009) Gender differences, responsiveness and memory of a potentially painful event in hermit crabs. Anim Behav 78:1373-1379.

Braithwaite, V.A. (2007) Pain perception, aversion and fear in fish. Dis Aquat Organ 75:131138.

Casares, F.M., McElroy, A., Mantione, K., Baggermann, G., Zhu, W. and Stefano, G.B. (2005) The American lobster, Homarus americanus, contains morphine that is coupled to nitric oxide release in its nervous and immune tissues: Evidence for neurotransmitter and hormonal signaling. Neuroendocrinology Letters 2:89-97.

Damasio, A. and Carvalho, G.B. (2013) The nature of feelings: evolutionary and neurobiological origins. Nature Rev Neurosci 14:143-152.

Derbyshire, S.W.G. (2006) Can fetuses feel pain? Brit Med J 332:909-912.

Derbyshire, S.W.G. and Raja, A. (2011) On the development of painful experience. Journal of Consciousness Studies 18:233-256.

Devor, M., Rappaport, I. and Rappaport, Z.H. (2014) Does the golem feel pain? Moral instincts and ethical dilemmas concerning suffering and the brain. Pain Pract 15:497-508.

Dunlop, R. and Laming, P. (2005) Mechanoreceptive and nociceptive responses in the central nervous system of goldfish (Carassius auratus) and trout (Oncorhynchus mykiss). J Pain 6:561-568.

Elwood, R.W. (2011) Pain and suffering in invertebrates? ILAR Journal 52:175-184.

Giannakoulopoulos, X., Sepulveda, W., Kourtis, P., Glover, V. and Fisk, N.M. (1994) Fetal plasma cortisol and $\beta$-endorphin response to intrauterine needling. Lancet 344:77-81.

Grahek, N. (2007) Feeling pain and being in pain. Bradford Books, Cambridge. 
Key, B. (2016). Why fish do not feel pain. Animal Sentience 2016.003.

Lowery, C.L., Hardman, M.P., Manning, N., Hall, R.W. and Anand, K.J.S. (2007)

Neurodevelopmental changes of fetal pain. Seminars in Perinatology 31:275-282.

Merker, B. (2007) Consciousness without a cerebral cortex: A challenge for neuroscience and medicine. Behav Brain Sci 30:63-81.

Reissland, N., Francis, B. and Mason, J. (2013) Can healthy fetuses show facial expressions of "pain" or "distress"? PLOSone 8:e65530.

Rose, J.D. (2007) Anthropomorphism and 'mental welfare' of fishes. Dis Aquat Organ 75:139154.

Sneddon, L.U. (2009) Pain perception in fish: Indicators and endpoints. ILAR Journal 50:338342.

Sneddon, L.U., Braithwaite, V.A. and Gentle, M.J. (2003a) Do fish have nociceptors: evidence for the evolution of a vertebrate sensory system. Proc Roy Soc Lond B 270:1115-1121.

Sneddon, L.U., Braithwaite, V.A. and Gentle, M.J. (2003b) Novel object test: Examining nociception and fear in the rainbow trout. J Pain 4:431-440.

Tallis, R. (2005) The knowing animal: A philosophical inquiry into knowledge and truth. Edinburgh University Press, Edinburgh. 